\section{Using Leaf Temperature as a Nondestructive Procedure to Detect Root Rot Stress in Geranium}

\author{
Medani Omer ${ }^{1}$, James C. Locke, and Jonathan M. Frantz
}

ADDITIONAL INDEX WORDs. biotic stress, reflectance, infrared temperature, floriculture, remote sensing, Pelargonium

Summary. Diagnosis of incipient disease based on visual symptoms of geraniums (Pelargonium $\times$ hortorum) exposed to water mold pathogens is often difficult, especially when the plants are maintained under optimum growing conditions. Such plants tend to be asymptomatic until late in the infection process when control methods are less effective and the aesthetic value of the finished crop is diminished. To circumvent such a problem and to be able to predict the susceptibility of the plants to infection, we used infrared transducers to measure leaf surface temperature, in addition to other parameters, in geranium plants exposed to a number of soil pathogens that are commonly associated with greenhouse production. Differences in leaf temperature among treatments were noticeable by 2 week after inoculation and were the greatest in week 7 . However, visual disease symptoms were not detected until 3 weeks after inoculation. Results of this study suggest that leaf temperature measurements are a versatile, nondestructive way of rapidly determining whether plants are under pathogen stress before visual symptoms develop.

$\mathrm{T}$ he U.S. Department of Agriculture (USDA) estimated that 185 million geraniums were produced in 2000 with a total wholesale value of $\$ 250$ million (USDA, 2003). Geraniums are susceptible to pathogens [e.g., water molds (Pythium and Phytophthora) (Daughtrey, 2003a; Moorman, 1998)] that can cause major disease problems. Many species of Pythium cause damping-off of germinating seeds, infect young roots, cause root rot in older plants, and, by proliferating into the stem base and growing upward, cause black leg symptoms on geraniums (Daughtrey, 2003b). Aboveground symptoms of Pythium infection include yellowing and browning of lower leaves, wilting, and plant death (Daughtrey, 2003b). However, mild root rot, causing only plant stunting, might go undetected unless compared directly with healthy,

USDA-ARS, ATRU, Greenhouse Production Research Group, 2801 W. Bancroft, Mail Stop 604, Toledo, $\mathrm{OH} 43606$

Mention of a trademark, proprietary product, or vendor does not constitute a guarantee or warranty of the product by the USDA and does not imply its approval to the exclusion of other products or vendors that also may be suitable.

We thank Ann Widrig, Lee Buckingham, Stephen Ohene-Larbi, Tera McDowell, and Kurt Thomas for greenhouse technical assistance.

${ }^{1}$ Corresponding author. E-mail: medani.omer@ ars.usda.gov. uninoculated plants (Hausbeck et al., 1989). Growers may attribute poor growth in asymptomatic plants to inadequate nutrition or insufficient watering, often resulting in overfertilization and overwatering (Jones, 2001). Wet soil conditions can favor the production, survival, and dissemination of zoospores and sporangia.

Root rot can reduce efficient water uptake by roots compromising the evaporative cooling ability of the plant (Mengistu et al., 1987). Therefore, leaf temperature is a potentially sensitive indicator of plant moisture stress.

Using a simplified energy balance model (Monteith, 1977), a sensitivity analysis of leaf temperature and transpiration can be performed. Assuming some typical values, a geranium leaf that is 4 inches wide might absorb $1000 \mathrm{~W} \cdot \mathrm{m}^{-2}$ of radiation if the plant is experiencing $\approx 80 \%$ full sun [(Lambers et al., 1998) both long and shortwave radiation]. Assuming realistic values for other environmental parameters of $25^{\circ} \mathrm{C}$ temperature, $50 \%$ relative humidity, and a leaf temperature $3{ }^{\circ} \mathrm{C}$ above air temperature (Jifon and Syvertsen, 2003), the plant loses $\approx 100 \mathrm{~W} \cdot \mathrm{m}^{-2}$ through transpiration. If transpiration decreases by only $5 \%$ and all other environmental conditions remain the same, leaf temperature would rise by nearly $0.1{ }^{\circ} \mathrm{C}$. Further decreases in transpiration result in a linear increase in leaf temperature of $\approx 0.02{ }^{\circ} \mathrm{C}$ per percent decrease in transpiration.

The objective of this study was to determine if changes in geranium leaf temperature, measured by infrared (IR) transducers aimed at the plant canopy or individual leaves, correlate with root infection by pathogenic water molds. If successful, leaf temperature could be used to nondestructively indicate infection of greenhouse-grown plants, perhaps before visible symptom development.

\section{Materials and methods}

Plant growth conditions. Seeds of 'Maverick Red' geranium (Ball Horticultural Company, Batavia, IL) were sown singly in foam cubes $(15 \times 15 \times 30 \mathrm{~mm}$ each, LCltype; Smithers-Oasis North America, Kent, OH). Two-week-old seedlings were transplanted individually to 4inch-diameter pots filled with soilless substrate containing 2:2:1 (by volume) vermiculite, sphagnum peat, and perlite (Blend 1, Sunshine Media Mix; Fisons Western Corp., Vancouver, BC). Six plant pathogens commonly introduced into greenhouses through contaminated growth media or tools were trialed: Pythium aphanidermatum, Pythium ultimum, Phytophthora cactorum, Phytophthora cinnamomi, Phytophthora citrophthora, and Verticillium dabliae. Pathogens were cultured on potato dextrose agar [PDA (DIFCO, Sparks, MD)] for 7 to $10 \mathrm{~d}$ at $25^{\circ} \mathrm{C}$. A cork borer

\begin{tabular}{llll}
\hline $\begin{array}{l}\text { Units } \\
\begin{array}{l}\text { To convert U.S. to SI, } \\
\text { multiply by }\end{array}\end{array}$ & U.S. unit & SI unit & $\begin{array}{l}\text { To convert SI to U.S., } \\
\text { multiply by }\end{array}$ \\
\hline 0.3048 & $\mathrm{ft}$ & $\mathrm{m}$ & 3.2808 \\
2.5400 & inch(es) & $\mathrm{cm}$ & 0.3937 \\
25.4000 & inch(es) & $\mathrm{mm}$ & 0.0394 \\
28.3495 & $\mathrm{oz}$ & $\mathrm{g}$ & 0.0353 \\
1 & $\mathrm{ppm}$ & $\mathrm{mg} \cdot \mathrm{L}^{-1}$ & 1 \\
10.7639 & $\mathrm{~W} / \mathrm{ft}^{2}$ & $\mathrm{~W} \cdot \mathrm{m}^{-2}$ & 0.0929 \\
$\left({ }^{\circ} \mathrm{F}-32\right) \div 1.8$ & ${ }^{\circ} \mathrm{F}$ & ${ }^{\circ} \mathrm{C}$ & $\left(1.8 \times{ }^{\circ} \mathrm{C}\right)+32$
\end{tabular}


(Fisher Scientific, Pittsburgh, PA) was used to transfer four or five 0.4 -inchdiameter mycelial disks from the edge of the colonies to the stem-root interface of each plant. Sterile PDA disks were used as a control. The disks were then covered lightly with the soilless substrate to minimize desiccation. Pots containing plants treated with the same pathogen were placed in plastic trays with 1 inch of water in the bottom for $48 \mathrm{~h}$ to simulate flooded conditions favorable for the release of zoospores and sporangia (Benson and von Broembsen, 2001; Jones, 2001). After $48 \mathrm{~h}$, the plants were removed from the trays and returned to the greenhouse bench. Plants were fertilized daily with fertilizer solution based on 100 ppm nitrogen (Peter's 20N-8.8P$16.6 \mathrm{~K}$ water-soluble fertilizer; Scotts Company, Marysville, $\mathrm{OH}$ ) and maintained at $23^{\circ} \mathrm{C}$ temperature with a 16-h photoperiod. No insect problems were detected for the duration of the experiment, so no insecticide was applied. Plants were periodically inspected for symptom development and disease progress.

Plant and environmental MONITORING. After inoculation, plants were moved, one at a time, to a measurement station located no more than $2 \mathrm{~m}$ from the growth area in the same greenhouse. The station (Fig. 1) was equipped with a quantum sensor (model QSO; Apogee Instruments, Logan, UT) to measure photosynthetically active radiation; a pyranometer (model PYR; Apogee Instruments) to measure shortwave radiation; and a humidity/temperature probe (model CS500; Campbell Scientific, Logan, UT) and two thermocouples (type K) to measure and record the environment. One thermocouple was used to measure air temperature (shielded and aspirated with a foil covered box and fan) and the other was used as a switch; when it was held or touched, the thermocouple heated, which switched the datalogger (CRI0X; Campbell Scientific) from only monitoring to both monitoring and saving the environmental data. Having a single station rather than measuring each plant in its growing location within the greenhouse minimized environmental variability on a single day among plants.

An IR surface temperature probe (model IRT-P5; Apogee

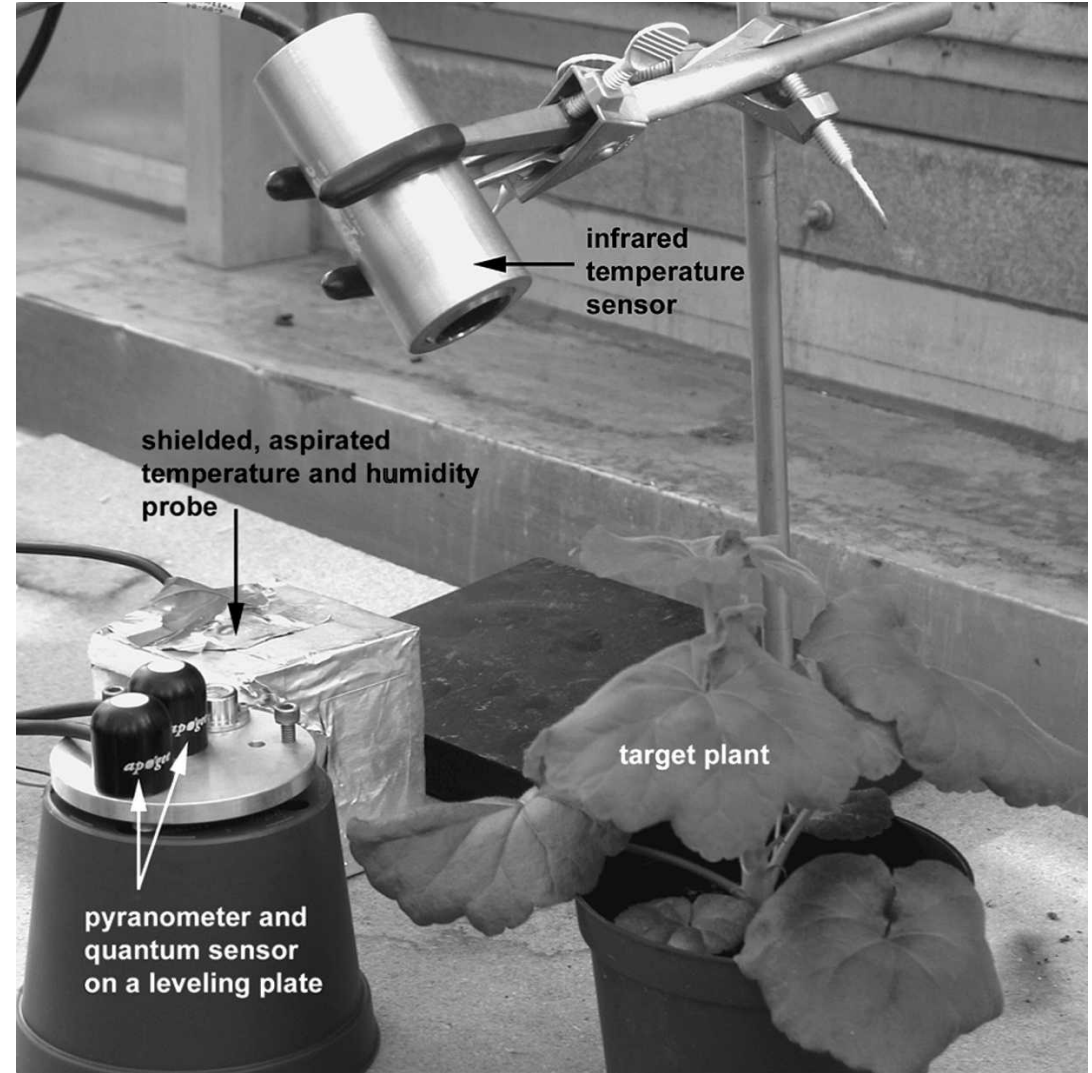

Fig. 1. Geranium plants being measured at the measurement station. An infrared transducer is pointed at a target leaf or leaves to measure the surface temperature. Pyranometer and quantum sensors are positioned on a leveling plate close to the target. Air temperature and humidity are recorded with a temperature and humidity probe. Data are recorded once per second for $\approx 20$ to 30 s per plant.

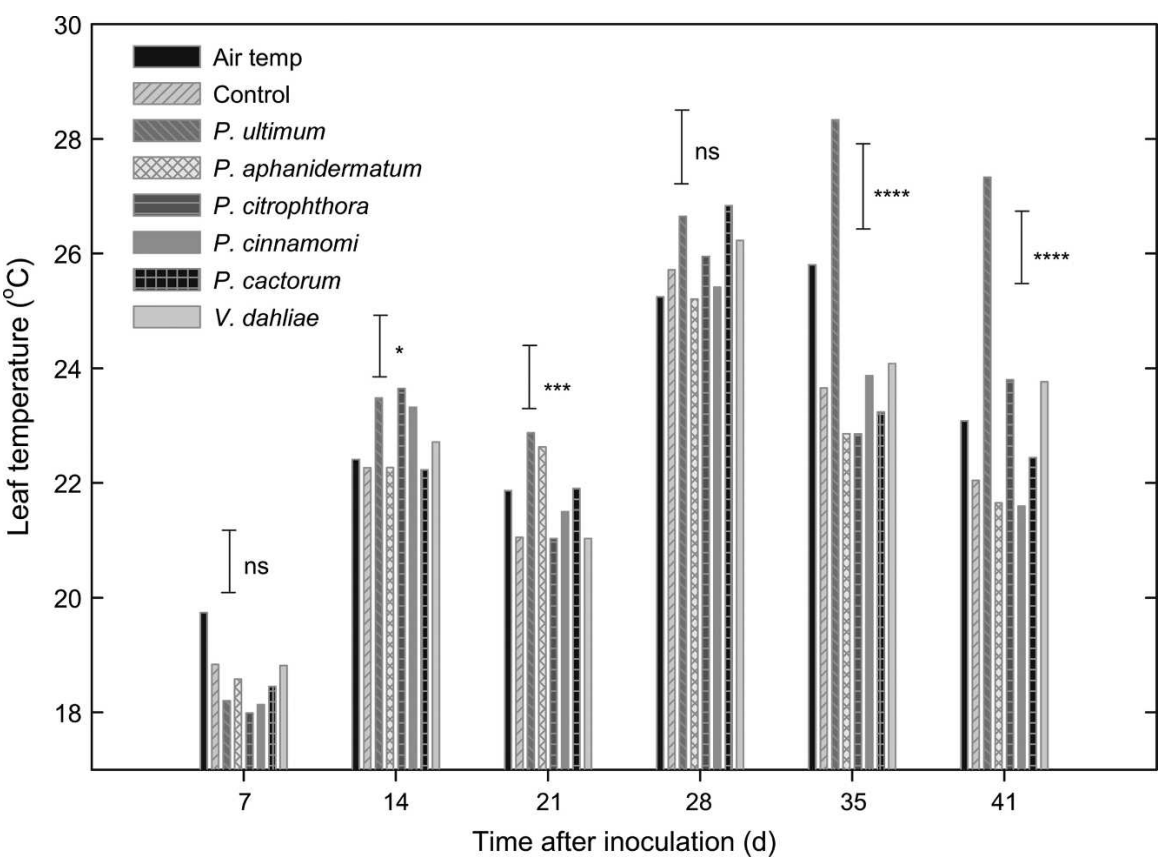

Fig. 2. Leaf temperature $\left({ }^{\circ} \mathrm{C}\right)$ of control and plants inoculated with Pythium aphanidermatum, Pythium ultimum, Phytophthora cactorum, Phytophthora cinnamomi, Phytophthora citrophthora, and Verticillium dabliae on days 7, 14, $21,28,35$, and 41 with air temperature on those days shown as a reference. Error bar is one least significant difference for each of the days. * Significance at the $P<0.05,{ }^{* *} P<0.001$, and ${ }^{*} * * P<0.0001 ;\left(1.8 \times{ }^{\circ} \mathrm{C}\right)+32={ }^{\circ} \mathrm{F}+32=\mathrm{F}$. 
Instruments) measured leaf surface temperature (Fig. 1). The probe was positioned 4 inches from the top of the plant and at a $65^{\circ}$ angle to prevent probe shading the target area. After the plant was placed in the measurement station, it was allowed to stabilize for $\mathrm{l} \mathrm{min}$ before the surface temperature was recorded. The probe had a 5:1 field of view, which meant that in these measurement conditions, approximately two-thirds of the signal from the surface was detected in a 1 -inch-diameter circle directly in front of the IRT-P5. It is likely that most of the recorded surface temperature data came from a single leaf, but some came from surrounding leaves. The target was a leaf or leaves that represented the top portion of the plant canopy. For the purposes of this article, we refer to the surface temperature as "leaf surface temperature." Surface temperature can change as a function of leaf size (Nobel, 1991). Specifically, as leaves get larger, their boundary layer increases and loses energy slower through conduction and convection. We would expect, then, that any stunting of leaves would assist in cooling leaf. However, the magnitude of change is small because the impact of leaf size is determined by the square root of leaf width and the amount of change in a geranium plant is likely to be only a few millimeters.

Leaf surface temperature and environmental data were measured once a second for 20 to $30 \mathrm{~s}$ while the plant was at the measurement station. These data were then averaged for a single measurement for that plant on a given day. A shorter measurement period could have been used for similar results. Our thermocouple-based "switch" (described previously) was convenient, but occasionally took several additional seconds to cool, which increased the sample period for some samples.

EXPerimental DESIGN. Plants were arranged on greenhouse benches in a randomized complete-block design with four replications per treatment and two plants per replicate. The experiment was performed once in 2005 and again in 2006. In 2005, the average photosynthetic photon flux $(P P F)$ was $61 \pm 39 \mu \mathrm{mol} \cdot \mathrm{m}^{-2} \cdot \mathrm{s}^{-1}$ (range, 20 to $196 \mu \mathrm{mol} \cdot \mathrm{m}^{-2} \cdot \mathrm{s}^{-1}$ ) with an average shortwave radiation of 41 $\mathrm{W} \cdot \mathrm{m}^{-2} \pm 26\left(\right.$ range, 11 to $\left.164 \mathrm{~W} \cdot \mathrm{m}^{-2}\right)$.
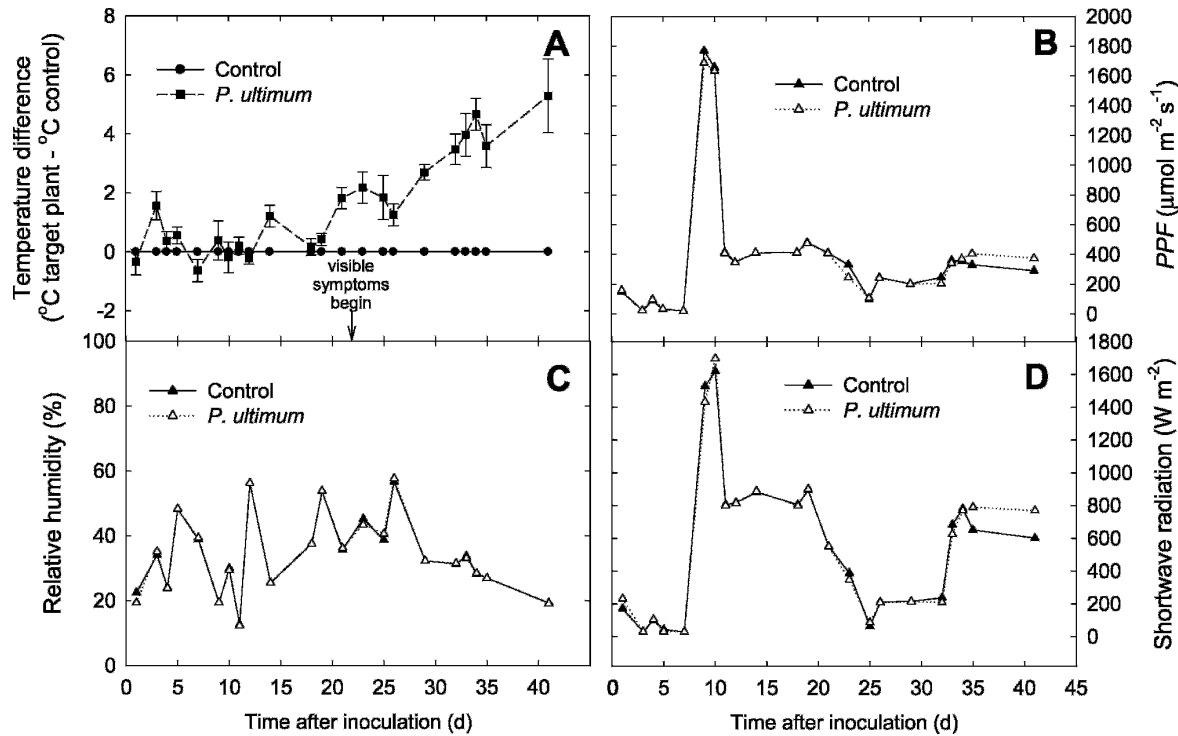

Fig. 3. The difference in (A) temperature between control and Pythium ultimum-inoculated plants, (B) photosynthetic photon flux, (C) relative humidity, and (D) shortwave radiation of the environment during the measurement period. Two weeks after inoculation, leaf temperature of $P$. ultimum-inoculated plants began to be warmer than the control plants and continued to rise for the duration of the trial. Disease symptoms were initially visible $22 \mathrm{~d}$ after inoculation. Error bars are \pm 1 SE of the mean $(n=4)$. The environment did not differ between control and $P$. ultimum-inoculated plant measurement periods except for a slight, but significant, difference on the final two measurements; $\left(1.8 \times{ }^{\circ} \mathrm{C}\right)+32={ }^{\circ} \mathrm{F}$, $1 \mathrm{~W} \cdot \mathrm{m}^{-2}=0.0929 \mathrm{~W} / \mathrm{ft}^{2}$.

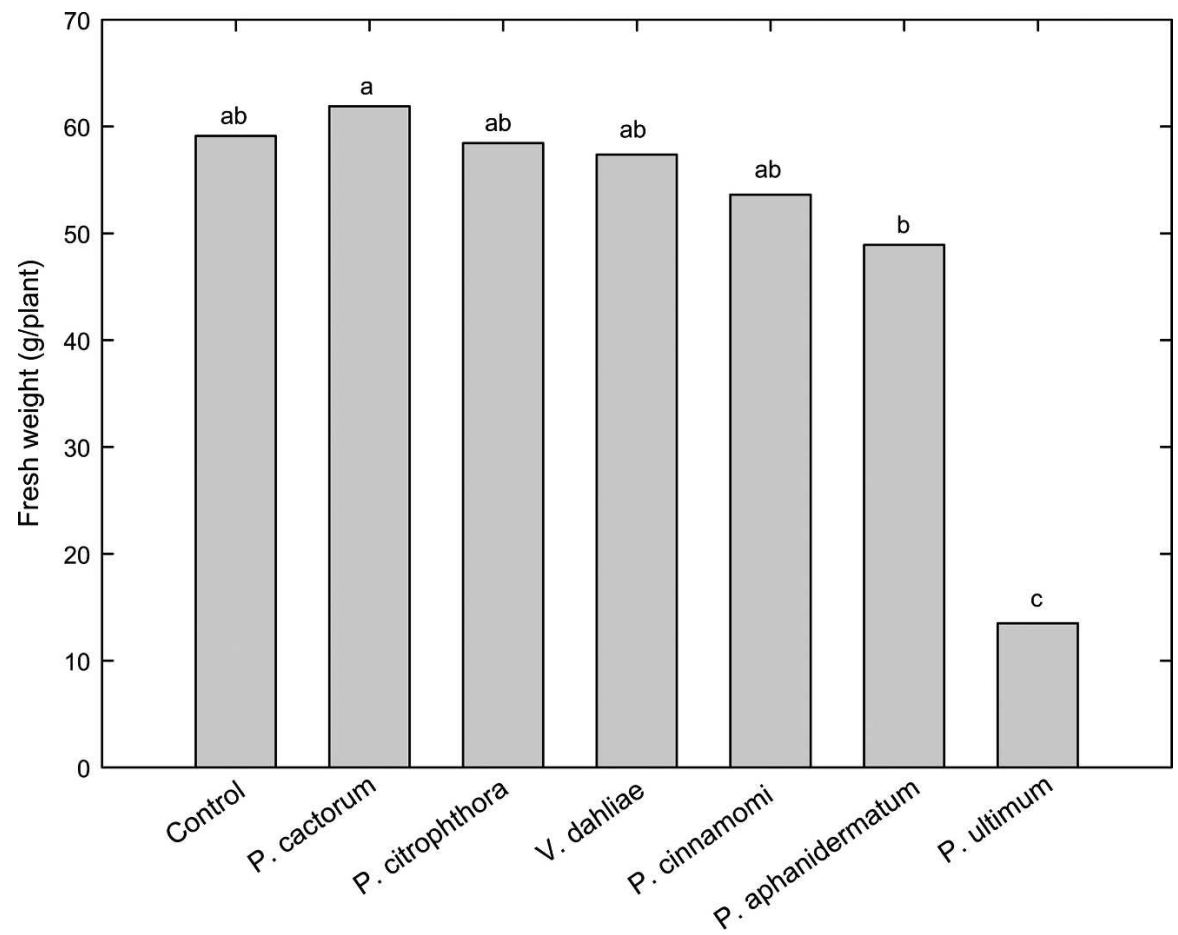

Fig. 4. Fresh weight (g) of geranium shoot system of all treatments at harvest $45 \mathrm{~d}$ after inoculation with Pythium aphanidermatum, Pythium ultimum, Phytophthora cactorum, Phytophthora cinnamomi, Phytophthora citrophthora, and Verticillium dabliae. Different letters indicate differences of mean based on least significant difference $(P<0.05) ; 1 \mathrm{~g}=-0.0353 \mathrm{oz}$. 
This is in the range of commonly reported light compensation points for plant canopies of 50 to nearly $200 \mu \mathrm{mol} \cdot \mathrm{m}^{-2} \cdot \mathrm{s}^{-1}$ (Evans and Farquhar, 1991; Wheeler et al., 1993) and well below minimum growth guidelines for floriculture crops (Fisher and Both, 2004). This production environment was not considered to be representative of what is typical for geranium production and this data set was not considered. In 2006, an effort was made to increase $P P F$ and shortwave radiation through placement of the measurement station within the greenhouse, use of uniform, electric light sources to supplement sunlight, and measuring plants in the middle of the day. Therefore, the results from the 2006 experiment are presented here. The effect of pathogens on leaf surface temperature and other parameters was determined by the analysis of variance using the Statistix 8 Analytical Software (Analytical Software, Tallahassee, FL).

\section{Results and discussion}

No significant difference $(P>$ 0.05 ) in leaf temperature was observed among treatments $7 \mathrm{~d}$ after inoculation (Fig. 2) indicating that up to this point, inoculated plants acclimated to the daily environment to the same extent as control plants. There were large differences in the environment and leaf temperatures from day to day as a result of changes in cloud cover, ambient temperature, and humidity, but no differences in the measurement environment between control and inoculated plants in a given day (data not presented). By day 14 , there was an increase in leaf surface temperature compared with day 7 in all treatments, including the control, with the plants treated with P. ultimum and P. citrophthora having higher leaf temperatures in comparison with other treatments. Twenty-one days postinoculation, leaf temperature for plants infected with $P$. ultimum was consistently higher than that of the control plants. Leaf temperature in plants infected with $P$. ultimum continued to rise relative to control leaf temperature for the duration of the study.

Pythium ultimum was the only pathogen that consistently caused significant disease symptoms and a slow, steady rise in temperature compared with the control after day 14 (Fig. 3).
After this point, temperature rose an average $0.35^{\circ} \mathrm{C}$ per day. There were no differences in the other environmental parameters between control and P. ultimum-inoculated plants in a given day (Fig. 3B-D).

Twenty-eight days postinoculation, root systems of $P$. ultimuminfected geraniums were decomposing and showed extensive damage (Fig. 4). Plants infected with P. ultimum were the smallest and had significantly lower shoot weight than all other treatments suggesting that this treatment caused more root infection.

Visible disease symptoms in the form of chlorosis and stunted growth were not evident until $22 \mathrm{~d}$ after inoculation and only in plants challenged with $P$. ultimum. Six weeks after inoculation, growth in all the plants, except for the ones inoculated with $P$. ultimum, was comparable to control (Fig. 5A-D). Pythium aphanidermatum is often associated with greenhouse production and was reported to be
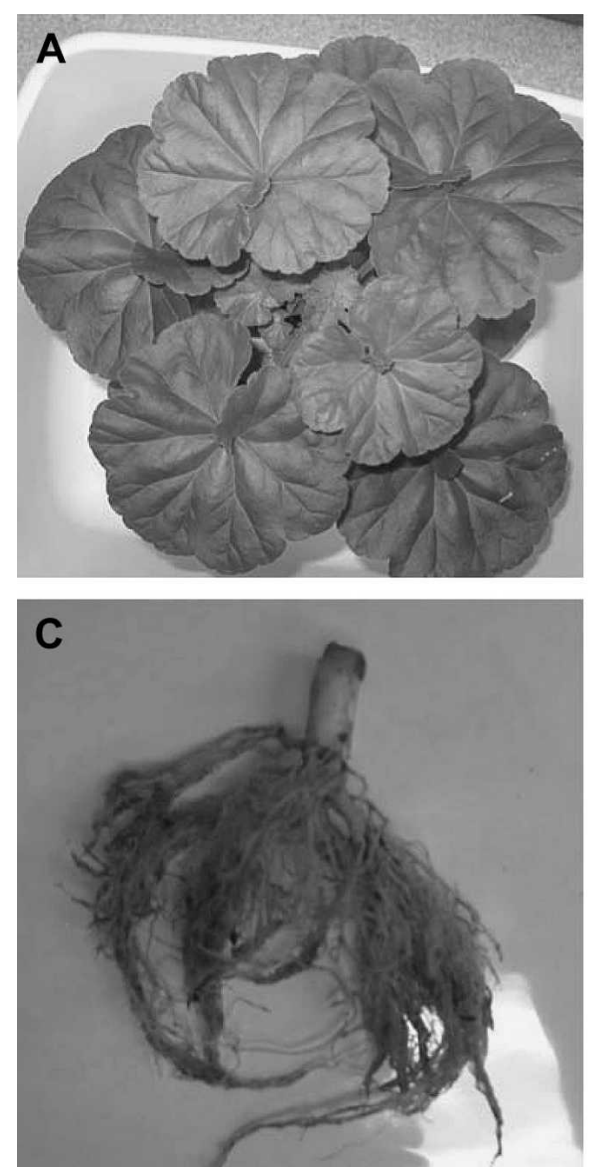

Fig. 5. Plant appearance of (A) control and (B) and Pythium ultimum-inoculated shoots as well as (C) control roots and (D) P. ultimum-inoculated roots $45 \mathrm{~d}$ after inoculation. No visible signs of stress were evident on the control plants, but $P$. ultimum-inoculated plants began showing stunting and chlorosis $22 \mathrm{~d}$ after inoculation and had a severely reduced root weight.
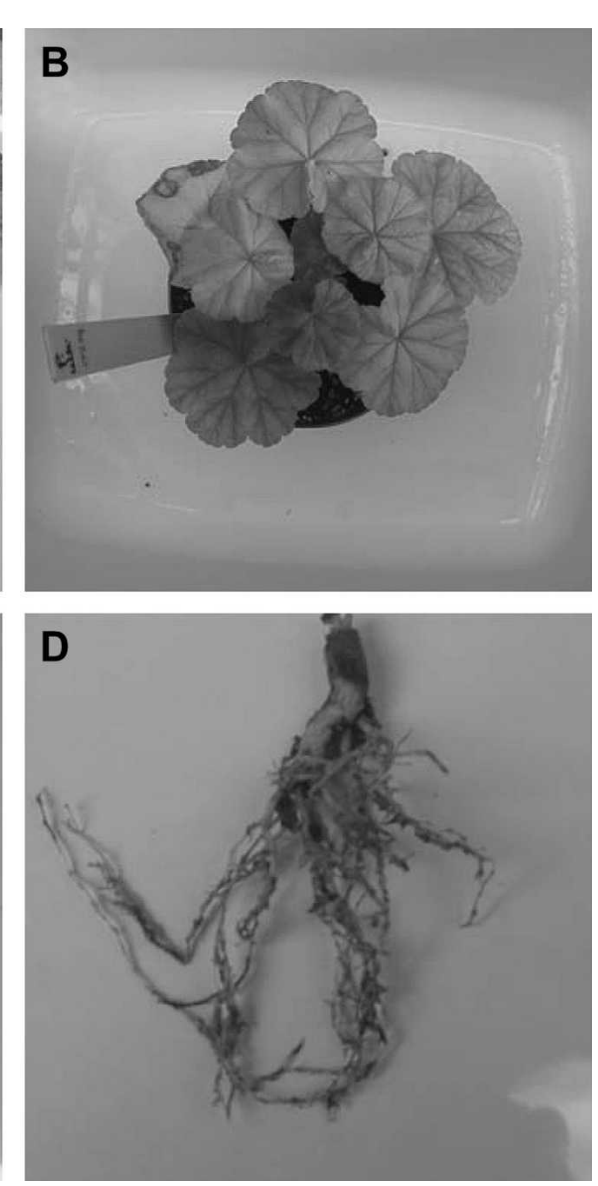

pathogenic on geranium (Moorman et al., 2002). However, it produced no disease symptoms on geranium in this study. This could be the result of the host specificity of the isolate tested (Stephens and Powell, 1982) or to the somewhat cool temperatures in our greenhouse that were less favorable to $P$. aphanidermatum in comparison with P. ultimum (BenYephet and Nelson, 1999).

When geranium is maintained under optimum growing conditions, it becomes difficult to visually diagnose symptoms resulting from exposure to pathogens such as P. ultimum. As a result, the observed effect of the pathogen on its host can be negligible or largely minimized, although it might be present. Many factors such as water stress, nutrient deficiency, insects, and diseases influence the leaf temperature (Jackson, 1986). In this study, all of these factors, except disease, were controlled or standardized on each day, yet leaf temperatures 
differed between the control and P. ultimum-inoculated plants.

We conclude that the increase in leaf surface temperature in response to stress was incited by the exposure of geranium to pathogens. This is the first report to our knowledge that addresses the use of environmental sensors to detect disease stress on a geranium-water mold pathosystem. We believe that the use of leaf surface temperature could be a reasonable nondestructive, noninvasive technique to predict plant stress resulting from infection by pathogens before symptom appearance. However, leaf temperature should only be used in conjunction with other tests and observations to rule out other factors contributing to a rise in leaf temperature.

\section{Literature cited}

Ben-Yephet, Y. and E.B. Nelson. 1999. Differential suppression of damping-off caused by Pythium aphanidermatum, $P$. irregulare, and P. myriotylum in composts at different temperatures. Plant Dis. $83: 356-360$

Benson, M.D. and S. von Broembsen. 2001. Phytophthora root rot and dieback, p. 52-56. In: R.K. Jones and D. Benson (eds.). Diseases of ornamentals and trees in nurseries. APS Press, St. Paul, MN.

Daughtrey, M. 2003a. Southern bacterial blight caused by Ralstonia solanacearum. 27 Feb. 2007. <http://www.greenhouse. cornell/pesticide/MD.SAFtalk.pdf>.
Daughtrey, M. 2003b. Managing diseases, p. 127-138. In: D. Hamrick (ed.) Ball redbook, 17th ed. Vol 2. Ball Publishing, Batavia, IL.

Evans, J.R. and G.D. Farquhar. 1991. Modeling canopy photosynthesis from the biochemistry of the C3 chloroplast. In: K.J. Boote and R.S. Loomis (eds.). Modeling crop photosynthesis-From biochemistry to canopy. Crop Sci. Soc. Amer. Spec. Publ. 19. Crop Sci. Soc. Amer., Madison, WI.

Fisher, P. and A.J. Both. 2004. Supplemental lighting technology and costs, p. 43-46. In: P. Fisher and E. Runkle (eds.). Lighting up profits. Understanding greenhouse lighting. Meister Media Worldwide, Willoughby, $\mathrm{OH}$.

Hausbeck, M.K., C.T. Stephens, and R.D. Heins. 1989. Relationship between silver thiosulfate and premature plant death of seed propagated geraniums caused by Pythium ultimum. Plant Dis. 73:627-630.

Jackson, R. 1986. Remote sensing of biotic and abiotic plant stress. Ann. Rev. Phytopathol. 24:265-287.

Jifon, J.L. and J.P. Syvertsen. 2003. Kaolin particle film applications can increase photosynthesis and water use efficiency of 'Rube Red' grapefruit leaves. J. Amer. Soc. Hort. Sci. 128:107-112.

Jones, R.K. 2001. Control of fungal diseases, p. 52-56. In: R.K. Jones and D. Benson (eds.). Diseases of ornamentals and trees in nurseries. APS Press, St. Paul, MN.

Lambers, H., F.S. Chapin, III, and T.L. Pons. 1998. Plant physiological ecology. Springer, New York.
Mengistu, A., H. Tachibana, A.H. Epistein, K.G. Bidne, and J.D. Hatfield. 1987. Use of leaf temperature to measure the effect of brown stem rot and soil moisture stress and its relations to yields of soybeans. Plant Dis. 71:632-634.

Monteith, J.L. 1977. Climate and the efficiency of crop production in Britain. Phil. Trans. Royal Soc. London. 281:277-294.

Moorman, G. 1998. Common names of plant diseases: Diseases of geranium (Pelargonium). 12 Jan. 2007. <http:// www.apsnet.org/online/common/ names/geranium.asp $>$.

Moorman, G.W., S. Kang, D.M. Geiser, and S.H. Kim. 2002. Identification and characterization of Pythium species associated with greenhouse floral crops in Pennsylvania. Plant Dis. 86:1227-1231.

Nobel, P.S. 1991. Physiochemical and environmental plant physiology. Academic Press, San Diego.

Stephens, C.T. and C.C. Powell. 1982. Pythium species causing damping-off of seedling bedding plants in Ohio greenhouses. Plant Dis. 66:731-733.

U.S. Department of Agriculture. 2003. Floriculture crops: 2002 summary. U.S. Dept. Agr., Natl. Agr. Sta. Serv., Washington, DC.

Wheeler, R.M., K.A. Corey, J.C. Sager, and W.M. Knott. 1993. Gas exchange characteristics of wheat stands grown in a closed, controlled environment. Crop Sci. 33:161-168. 